\title{
Health-related quality of life (HRQoL) in children and adolescent with post-traumatic stress symptom: A comparison of 16D and condition-specific instruments
}

\author{
ELINE AAS ${ }^{1 *}$ \\ SANJU SILWAL ${ }^{1,2}$ \\ PASCAL R CYR ${ }^{1,3}$ \\ TONJE HOLT ${ }^{4}$ \\ SILJE M. ORMHAUG ${ }^{5}$ \\ TINE K. JENSEN ${ }^{5,6}$ \\ ${ }^{1}$ Institute of Health and Society, Department of Health Management and Health Economics, \\ University of Oslo, Oslo, Norway \\ ${ }^{2}$ Department of Child Psychiatry, Research Centre for Child Psychiatry, University of Turku, Turku, Finland \\ ${ }^{3}$ Institute of Health and Society, Community Medicine and Global Health, \\ University of Oslo, Oslo, Norway \\ ${ }^{4}$ Division of Mental and Physical Health, Norwegian Institute of Public Health, Oslo, Norway \\ ${ }^{5}$ Norwegian Centre for Violence and Traumatic Stress Studies (NKVTS), Oslo, Norway \\ ${ }^{6}$ Department of Psychology, University of Oslo, Oslo, Norway
}

\begin{abstract}
The objective of this study was to compare Health-Related Quality of Life (HRQoL) as measured by the 16D instrument with four condition-specific instruments in children and adolescents with significant post-traumatic stress disease (PTSD), to assess the validity of the $16 \mathrm{D}$ instrument. In addition, we test for differences in health for the PTSD population compared to a representative sample of Finnish schoolchildren. The study included 156 children and adolescents with trauma-related symptoms in Norway. The condition-specific instruments included were; Child PTDS Symptom Scale (CPSS); Mood and Feelings Questionnaire (MFQ); Screen for Child Anxiety Related Emotional Disorders (SCARED), and; Strengths and Difficulties Questionnaire (SDQ). We found that the 16D HRQoL score was significantly correlated with all condition-specific instruments (CPSS, SCARED, MFQ, and SDQ), where SCARED had the highest correlation with the 16D ($0.659, \mathrm{p}<0.01$ ). Several of the corresponding items (sleep, distress, discomfort and symptoms, mental functioning, and school and hobbies) of the condition-specific instruments were correlated above the threshold (convergent validity, $\rho>0.4$ ). Children and adolescents with symptoms of post-traumatic stress experienced a significant health loss of 0.177 compared to a representative sample of Finnish 12 to 15 -years-old schoolchildren with a Cohen's d of 1.07, and the health difference was significant for all 16 dimensions. These findings support the use of the $16 \mathrm{D}$ to measure health outcomes in cost-utility analysis. More studies are needed to examine the responsiveness.
\end{abstract}

JEL classification: D61, I12, I14

Key words: HRQoL, 16D, condition-specific, children, adolescents, post-traumatic stress symptom

\section{Introduction}

* Correspondence to: Eline Aas, Institute of Health and Society, Department of Health Management and Health Economics, University of Oslo, PO Box 1089, Blindern, 0317 Oslo. Email: eline.aas@medisin.uio.no. Published: Online August 2020. dx.doi.org/10.5617/njhe.6929 
In several countries, cost-effectiveness analysis (CEA) is the recommended method to guide reimbursement decisions (CADTH, 2017; Guidelines NOMA, 2018; Guidelines Dutch, 2016). In the CEA guidelines, the health outcome should be measured by a generic instrument, while the resource use could either adapt a health care- or a societal perspective. Most commonly, the health outcome is measured in quality adjusted life years (QALYs), combining health related quality of life (HRQoL) and time. HRQoL is usually computed with a multi-attribute instrument (16D, EQ-5D, or SF-6D, Drummond et al., 2015), including items that represent dimensions of health (e.g., depression, mobility, pain, etc.), and level of severity (e.g., not a problem, moderate problem, and severe problem). Each health state (combination of items and severity) is then scored between 0 and 1 , where 0 refers to death and 1 to perfect health (Drummond et al., 2015), and where one QALY is defined as being in perfect health for one year. Weights are elicited from valuation studies in the general population.

Generic instruments are being used increasingly in economic evaluations worldwide (Harding, 2001; Rios-Diaz et al., 2016), but have not been commonly used in mental health research and even less frequently in research regarding children and adolescents. In addition, concerns have been expressed about whether generic instruments are appropriate for assessing complex outcomes regarding mental health problems (Crawford et al., 2011), as condition-specific instruments are responsive to changes in the health conditions they are meant to evaluate. Several studies have demonstrated the relevance and validity of generic measures for mental health conditions such as schizophrenia, depression, and anxiety, but others show conflicting evidence for other mental illnesses including psychosis (Saarni et al., 2010; Brazier et al., 2014; Mulhern et al., 2014; Byford, 2013; Bastiaansen et al., 2004; Solans et al., 2008). When generic health instruments have to be considered in the context of assessing the mental health of children and adolescents, a number of methodological and ethical issues arise, including problems associated with the emotional and cognitive development of the children involved and the accuracy and acceptability of parent-proxy ratings (Eiser, 1997; Petrou, 2003).

Every year, a large number of children and adolescents experience traumatic events, and when left untreated, such events can affect their psychological and social well-being (Copeland et al., 2007; McLaughlin et al., 2013; Fairbank and Fairbank, 2009). The most common symptoms reported by children and adolescents after exposure to various traumatic events are post-traumatic stress symptoms (PTSS) (Kilpatrick et al., 2003), but anxiety and mood disorders (Ackerman et al., 1998) as well as severe behavioral problems (Gilbert et al., 2009) are also frequently reported. Clinical levels of PTSS have been reported after exposure to traumatic events including violence (Kilpatrick et al., 2003), war or other military conflict (Ajdukovic, 1998), abuse (Ackerman et al., 1998), traffic accidents (Meiser-Stedman et al., 2008), child sexual abuse (Finkelhor, 1994), burns (Saxe et al., 2005), and natural disasters (Jensen et al., 2009). Studies have indicated that post-traumatic stress disorder (PTSD) is, to a high degree, associated with impairment and disabling conditions that can endure into adulthood and can require costly interventions.

To date, little is known about the validity of generic instruments for evaluating the health status of children and adolescents with PTSD. In order to perform a CUA of new treatment regimens for this population, it is important to ensure that the HRQoL instrument is, in fact, a valid way to quantify health benefits. This means, for instance, that the instrument chosen must evaluate health dimensions that are relevant for the specific condition (content validity) and that corresponding dimensions of health in the generic- and condition-specific instruments are correlated (convergent validity). Thus, we aimed to compare the HRQoL, as measured by the 16D instrument, with four condition-specific instruments that were assessed in a sample of children and adolescents with significant 
PTSS during an RCT and to assess whether the 16D instrument is valid for use in a subsequent CUA. Longitudinal data were unavailable; therefore, we aimed to support the argument for the validity of the 16D using baseline responses of the participants. In addition, we estimated the difference in health status between the PTSD sample of Norwegian children and adolescents by comparing them to a representative sample of Finnish 12 to 15year-old schoolchildren.

\section{Material and Methods}

This study was part of a randomized control trial (ClinicalTrial.gov NO00635752) aimed at comparing the effect and costs of trauma-focused cognitive behavioral therapy (TF-CBT) and "therapy as usual" (TAU) in Norwegian children and adolescent that showed significant trauma-related symptoms. Details about the randomized clinical trial and objectives of the study are published elsewhere (Jensen et al., 2013). The Regional Committee for Medical and Health Research Ethics (South East, Norway) reviewed and approved the study design including written consent.

\subsection{Patients}

The target sample of the study was children and adolescents between the ages of 10 and 18 years. To be included, they had to be referred for treatment at one of eight child and adolescent community mental health clinics between April 2008 and February 2011, experienced at least one traumatizing event and having suffered from significant PTSS. Exclusion criteria included having suicidal behavior, acute psychosis, and need for an interpreter. Both children, adolescent and their parents provided written and active consent. The selection criteria for participation was made through a checklist based on items of Traumatic Events Screening Inventory for Children (Ribbe, 1996), and assessed for PTSS using the Child PTSD Symptom Scale (CPSS) (Foa et al., 2001). Those with scores of 15 and above on the CPSS and experiencing at least one symptom in each of the DSM-IV PTSD categories (re-experiencing, avoidance, and hyper arousal) were invited to participate in the study. A total of 454 adolescents were screened for eligibility, out of which 200 had a CPSS score of 15 and above. Finally, 156 adolescents met the inclusion criteria and agreed to participate in the study where data from baseline was used in this study.

\subsection{Health outcomes}

\section{HRQoL}

The 16-dimension (16D) instrument is a generic self-assessment instrument for adolescents aged 12-15 years (Apajasalo et al., 1996) (Appendix I). The 16D is one of two (17D) multiattribute generic self-assessment instruments for adolescents, the youth version of the adult instrument of 15D (Apajasalo et al., 1996). The 16D captures 16 dimensions (mobility, vision, hearing, breathing, sleeping, eating, speech, elimination, school and hobbies, mental function, discomfort and symptoms, depression, distress, vitality, appearance, and friends). Each dimension has five levels of severity ranging from no problems to severe problems. A health state is defined as a combination of answers on all 16 dimensions. Based on all possible health states, a single $16 \mathrm{D}$ score is estimated, representing HRQoL ranging from 0 (referring to death) to 1 (referring to perfect health, with no problems on any dimension). These weights were estimated based on preferences in the general population; hence the $16 \mathrm{D}$ is not a sum score. The 16D measure has been shown to be reliable (repeatability coefficient of 91\%), valid, and comprehensive (Apajasalo et al., 1996). 
The weights were obtained from a valuation study previously conducted on a Finnish sample of school children aged between 12 and 15 years $(n=239)$ and the algorithm was made available by the Finnish 15D organization (15d-instrument.net). The 16D score was generated from a set of preference weights on a scale of 0 -1, elicited through a three stage valuation procedure. The weights were derived by asking participants to value the importance of the 16 health dimensions (such as mobility versus vision) by indicating the position of each dimension on a VAS-scale (0-100), 100 being the most important dimension. These values were transformed so that the sum of the 16 individual weights summed up to one. In the next step, the importance of the levels within each dimension (difference in score between no problems and some problems) were valued similarly using a 0-100 VAS scale. Lastly, health states of being unconscious and death were valued for each dimension.

Before beginning the study, the 16D questionnaire had to be translated into Norwegian, as no Norwegian version was available. The translation was conducted according to the standards provided by the Finnish 15D organization (15d-instrument.net). The translation was organized in collaboration with clinicians running the clinical trial, health economists involved in the study, and English- and Norwegian-speaking advisors. Although the questionnaire is generic, the clinicians involved in the study have valuable knowledge about children and their cognitive understanding. The translation comprised several steps. First, a forward translation (the first Norwegian version) of the questionnaire was developed based on the English questionnaire. The clinicians, health economists, and an English-speaking advisor conducted the translation. In this step, several language adjustments were required, all to ensure that the word-framing was familiar and understandable for children and adolescent. Second, two independent translators not involved in the first step backward-translated the Norwegian version to English again. The backward-translated questionnaire was compared with the original, and based on this comparison, only minor adjustments were needed. Finally, the questionnaire was tested on a small sample of Norwegian children and adolescents, and we concluded that no additional changes were required. The final version was accepted by the Finnish 15D organization.

\section{Condition-Specific Instruments}

Condition-specific instruments were assessed using the Child PTSD Symptom Scale (CPSS), the Mood and Feelings Questionnaire (MFQ), the Strengths and Difficulties Questionnaire (SDQ), and the Screen for Child Anxiety Related Emotional Disorders (SCARED), see Appendix I for details.

\section{Child PTSD Symptom Scale (CPSS)}

The CPSS is a self-report questionnaire designed to assess PTSS for children and adolescents between 8 and 18 years described in the Diagnostic and Statistical Manual of Mental Disorders (DSM-IV)(Foa et al., 2001). The CPSS has 17 items scored on a fourpoint Likert scale: 0 (not at all), 1 (once in a week or less/once in a while), 2 (2-4 times a week/half the time), and 3 ( 5 or more times a week almost always). The maximum total score of CPSS is 51, adding responses (0-3) on all 17 questions. The cut-off score of 11 was originally suggested for distinguishing those with low vs. high PTSD symptoms (Foa et al., 2001); however, it was later suggested that a cut-off score of 15, as applied in this study, was a more optimal indicator for clinically elevated PTSS (Kassam-Adams et al., 2010).

The CPSS contains an additional scale that measures the influence of PTSS on daily functioning (fun activities and hobbies, relationships with friends, schoolwork, relationships with family, and general life satisfaction). A two-point scale was used: 1 reports impact on 
areas of daily functioning and 2 reports that there is no impact. CPSS has proven to be a good tool for assessment of PTSD severity and screening of PTSD diagnosis among traumatized children (Hukkelberg et al., 2014).

\section{Mood and Feelings Questionnaire (MFQ)}

The MFQ is a self-report questionnaire designed to assess a broad range of cognitive and vegetative symptoms of depression in children and adolescents between 8-18 years of age Castello and Angold, 1988). The questionnaire consists of 34 items, measured on a threepoint Likert scale: 0 (not true), 1 (sometimes), and 2 (true), and covers both a full range of DSM-IV diagnostic criteria for depressive disorders and additional items such as common affective, cognitive, and somatic features of childhood depression. A score of 27 or more is considered to be of clinical importance. The total high score of MFQ is 68.

\section{Strengths and Difficulties Questionnaire (SDQ)}

The SDQ is a self-report questionnaire that assesses the psychological adjustment of children and adolescents (Goodman, 2001). The SDQ contains 25 items, each clustered into five scales (dimensions) with five items each, generating scores for hyperactivity/inattention, emotional symptoms, conduct problems, peer relation problems, and pro-social behavior. The children scored each item on a three-point Likert scale: 0 (not true), 1 (somewhat true), and 2 (certainly true). The general difficulties total score is based on summing scores of the four problem-oriented sub-scores, and the subscale's range is 040. In a normal Norwegian sample, a total score of 18 or more was within the 90th percentile (Ronning et al., 2004).

\section{Screen for Child Anxiety Related Emotional Disorders (SCARED)}

The SCARED is a self-report instrument designed as a screening tool for childhood anxiety disorders (Birmaher et al., 1997). It consists of 41 items and 5 factors, parallel to DSM-IV classification of anxiety disorder: panic/somatic, generalized anxiety, separation, anxiety, social phobia, and a pertinent simple phobia and school phobia (Foa et al., 2001). The children scored items on a three-point Likert scale 0: (not true or hardly ever true), 1 (somewhat true or sometimes true), and 2 (very true or often true) with a total score of 82 . A total score of 25 was used as a cut-off to determine need for treatment and is considered to define the clinical range (Birmaher et al., 1997).

\subsection{Statistical Analysis}

Instruments used to evaluate health outcomes have to be reliable, meaning that they must be consistent and reproducible. All condition-specific instruments used in this analysis have been individually reported to have satisfactory internal consistencies and test-retest reliabilities (Foa et al., 2001; Hukkelberg and Jensen, 2011; Sund et al., 2001; Bøe et al., 2016; Birmaher et al., 1999, CADTH, 2017; Norwegian Medicines Agency, 2018; Dutch guidelines, 2016; Drummond et al., 2015; Harding, 2001).

To evaluate whether the 16D questionnaire is valid for evaluating the health outcome of new treatment options for children and adolescents with significant PTSD, we analyzed content, construct- and criterion validity (American Educational Research Association, Psychology Association and National Council on Measurement in Education, 1999).

Content validity considers to what extent an instrument is measuring the conceptual variable it is designed to measure (HRQoL). We study content validity by discussing the choice of the instrument 16D, and by reporting the descriptive statistics for the number of traumatic events, 16D, CPSS, MFQ, SDQ, and SCARED. In addition, we study the 
distributions for response and non-response. Patterns of missing values can be an indication that the questionnaires were unclear or that some items were too upsetting for respondents to answer. To be able to explore how the $16 \mathrm{D}$ responds to changes in disease-specific measures, each item must have a distribution of responses ranging over several levels on the severity scale.

Construct validity (convergent and discriminant validity) tests whether corresponding items of condition-specific instrument have constructs similar to the dimensions of the 16D, referred to as "corresponding dimensions". Of the 16 dimensions, five (sleeping, distress, school and hobbies, mental, and discomfort and symptoms) were most commonly addressed by condition-specific items (CPSS, SDQ, MFQ, and SCARED). Item-level correlations were then explored between the $16 \mathrm{D}$ dimensions and conditionspecific instruments using the Pearson correlation coefficient, $\rho$ (rho). To demonstrate item convergent validity, items measuring the same construct should be correlated with $\rho>0.4$ and non-corresponding items with $\rho<0.4$ (Mulhern et al., 2014; American Educational Research Association, Psychology Association and National Council on Measurement in Education, 1999). We will refer to a correlation of 0.4 as the threshold with respect to convergent validity and discriminant validity.

Criterion validation tests whether an instrument correlates with other instruments. We tested for correlations between the HRQoL 16D score and condition-specific instruments (CPSS, MFQ, SDQ, and SCARED).

Finally, the PTSD study population were compared for each of the $16 \mathrm{D}$ dimensions with scores in a representative sample of Finnish schoolchildren 12 to 15 years-old (Apajasalo et al., 1996). The difference in health for each dimension was expressed based on the difference in mean score within each dimension (best score of 1 and worst of 0 ). Mean group scores (representative sample versus PTSD sample) were tested for differences with t-test and assessed for effect sizes using Cohen's d coefficients, where $\mathrm{d}=0.02$ (small difference), $\mathrm{d}=0.5$ (moderate difference), and $\mathrm{d}=0.8$ (large difference).

All analyses for this study were conducted using the Statistical Package for Social Sciences (SPSS, Chicago, Illinois, USA) version 22.0.

\section{Results}

\subsection{Participants}

In total, the study included 156 children and adolescents ranging from 10 to 18 years, with a mean age of 15 years (SD 0.183). In the sample, $16 \%$ were below the age of 12 years; $35 \%$ were 12 to 15 years of age; and $49 \%$ were 16 to 18 years of age. The majority of the participants were female (80\%) and Norwegian (74\%).

\subsection{Content validity}

Content validity was based on the selection of the most appropriate generic instrument that contained dimensions of health that were relevant for the PTDS population. This selection was based on interdisciplinary group discussions.

On average, each participant had experienced four traumatic events, with a range from 1 to 10 . The mean baseline 16D score was 0.77 , ranging from 0.46 to 1.00 , indicating a significantly wide range for overall 16D HRQoL scores. The range of responses covered the range of severity levels in all condition-specific instrument, except for CPSS, where the inclusion criteria for the trial was defined at CPSS equal or greater than 15 (see Appendix I for details). 
Table 1: Number of traumatic events and health status according to conditionspecific and generic instrument at baseline in children and adolescent with PTSD

\begin{tabular}{llllll}
\hline Instrument & $\mathrm{N}$ & Mean & St.dev & Min & Max \\
\hline Total number of traumatic events experienced & 156 & 3.61 & 1.77 & 1 & 10 \\
16D & 149 & 0.77 & 0.11 & 0.46 & 1.00 \\
CPSS & 149 & 27.00 & 7.67 & 15 & 46 \\
MFQ & 149 & 35.37 & 12.17 & 0 & 59 \\
SDQ & 149 & 19.06 & 5.21 & 7 & 35 \\
SCARED & 147 & 33.72 & 16.26 & 2 & 70 \\
\hline
\end{tabular}

The distribution of responses and non-responses for 16D dimensions with similar items in the condition-specific instruments is presented in Table 2. Generally, we can observe low rates of missing observations, with $4.5 \%$ being the highest for the $16 \mathrm{D}$ instrument (all other dimensions of health and items are reported in Appendix 1).

Table 2: Distribution of responses in each item with missing responses at baseline for similar dimensions across all questionnaires. $\mathrm{N}=\mathbf{1 5 6}$

\begin{tabular}{|c|c|c|c|c|c|c|c|c|}
\hline \multirow[b]{2}{*}{ Instrument } & \multirow[b]{2}{*}{ Dimensions } & \multirow[b]{2}{*}{ Items } & \multicolumn{6}{|c|}{$\begin{array}{l}\text { Distribution of responses (\%) across } \\
\text { response levels on the severity scale }\end{array}$} \\
\hline & & & 1 & 2 & 3 & 4 & 5 & $\begin{array}{l}\text { Missi } \\
\text { ng }\end{array}$ \\
\hline \multirow[t]{5}{*}{$16 \mathrm{D}$} & Sleeping & $16 \mathrm{D}-6$ & 16.0 & 23.1 & 37.8 & 12.8 & 5.8 & 4.5 \\
\hline & Distress & $16 \mathrm{D}-4$ & 11.5 & 37.8 & 12.7 & 15.4 & 7.1 & 4.5 \\
\hline & Discomfort and symptoms & $16 \mathrm{D}-8$ & 27.6 & 34.0 & 25.6 & 8.3 & 0 & 4.5 \\
\hline & Mental & 16D-14 & 41.7 & 34.6 & 15.4 & 2.6 & 1.3 & 4.5 \\
\hline & School and hobbies & 16D-11 & 28.8 & 34.6 & 25.6 & 5.1 & 1.3 & 4.5 \\
\hline \multirow{7}{*}{ CPSS } & \multirow[t]{2}{*}{ Sleeping } & CPSS 2 & 26.3 & 34.6 & 26.9 & 12.2 & & \\
\hline & & CPSS13 & 10.3 & 19.2 & 26.3 & 44.2 & & \\
\hline & Distress & CPSS17 & 23.7 & 21.1 & 26.3 & 28.8 & & \\
\hline & Discomfort and symptoms & CPSS5 & 22.4 & 30.8 & 32.7 & 14.1 & & \\
\hline & Mental & CPSS15 & 6.4 & 15.4 & 37.2 & 41.0 & & \\
\hline & \multirow[t]{2}{*}{ School and hobbies } & CPSS7 & 28.2 & 30.1 & 15.4 & 26.3 & & \\
\hline & & CPSS9 & 29.5 & 26.9 & 27.6 & 16.0 & & \\
\hline \multirow{5}{*}{ MFQ } & Sleeping & MFQ32 & 62.8 & 16.0 & 21.2 & & & \\
\hline & Distress & MFQ7 & 19.2 & 35.9 & 44.9 & & & \\
\hline & Discomfort and symptoms & MFQ26 & 22.4 & 37.8 & 39.7 & & & \\
\hline & Mental & MFQ21 & 19.2 & 48.7 & 32.1 & & & \\
\hline & School and hobbies & MFQ29 & 21.8 & 35.9 & 42.3 & & & \\
\hline \multirow{8}{*}{ SDQ } & \multirow[t]{5}{*}{ Distress } & SDQ2 & 14.1 & 46.8 & 37.8 & & & 1.3 \\
\hline & & SDQ8 & 8.3 & 34.0 & 56.4 & & & 1.3 \\
\hline & & SDQ10 & 17.9 & 46.2 & 34.6 & & & 1.3 \\
\hline & & SDQ16 & 14.1 & 38.5 & 46.2 & & & 1.3 \\
\hline & & SDQ24 & 23.7 & 39.1 & 35.9 & & & 1.3 \\
\hline & Discomfort and symptoms & SDQ3 & 16.7 & 34.0 & 48.1 & & & 1.3 \\
\hline & \multirow[t]{2}{*}{ Mental } & SDQ15 & 6.4 & 28.8 & 63.5 & & & 1.3 \\
\hline & & SDQ25 & 56.4 & 38.5 & 3.8 & & & 1.3 \\
\hline
\end{tabular}




\begin{tabular}{|c|c|c|c|c|c|c|}
\hline \multirow{25}{*}{ SCARED } & \multirow{2}{*}{ Sleeping } & SCARED16 & 58.3 & 21.8 & 19.9 & 2.6 \\
\hline & & SCARED20 & 41.0 & 26.9 & 29.5 & 2.6 \\
\hline & \multirow[t]{15}{*}{ Distress } & SCARED7 & 18.6 & 47.4 & 32.1 & 1.9 \\
\hline & & SCARED9 & 62.2 & 26.3 & 9.6 & 1.9 \\
\hline & & SCARED10 & 32.7 & 41.0 & 24.4 & 1.9 \\
\hline & & SCARED14 & 30.1 & 37.2 & 30.8 & 1.9 \\
\hline & & SCARED19 & 19.2 & 41.7 & 36.5 & 2.6 \\
\hline & & SCARED23 & 21.2 & 42.9 & 33.3 & 2.6 \\
\hline & & SCARED24 & 46.8 & 32.7 & 17.9 & 2.6 \\
\hline & & SCARED25 & 52.6 & 25.0 & 19.9 & 2.6 \\
\hline & & SCARED28 & 39.7 & 36.5 & 21.2 & 2.6 \\
\hline & & SCARED30 & 45.5 & 26.9 & 25.0 & 2.6 \\
\hline & & SCARED33 & 17.9 & 42.9 & 36.5 & 2.6 \\
\hline & & SCARED35 & 19.2 & 41.0 & 37.2 & 2.6 \\
\hline & & SCARED37 & 19.2 & 50.6 & 28.2 & 1.9 \\
\hline & & SCARED39 & 30.1 & 36.5 & 31.4 & 1.9 \\
\hline & & SCARED40 & 49.4 & 28.2 & 20.5 & 1.9 \\
\hline & \multirow[t]{4}{*}{ Discomfort and symptoms } & SCARED6 & 57.7 & 28.8 & 35.9 & 1.9 \\
\hline & & SCARED27 & 63.5 & 18.6 & 15.4 & 2.6 \\
\hline & & SCARED34 & 62.8 & 15.4 & 19.2 & 2.6 \\
\hline & & SCARED38 & 48.1 & 28.8 & 21.2 & 1.9 \\
\hline & \multirow[t]{4}{*}{ School and hobbies } & SCARED2 & 21.1 & 44.2 & 32.7 & 1.9 \\
\hline & & SCARED11 & 40.4 & 30.1 & 27.6 & 1.9 \\
\hline & & SCARED17 & 48.7 & 30.1 & 18.6 & 1.9 \\
\hline & & SCARED36 & 63.5 & 20.5 & 13.5 & 2.6 \\
\hline
\end{tabular}

\subsection{Convergent validity}

Convergent validity is reported in Table 3. Correlation for corresponding 16D dimensions and items in CPSS, SDQ, MFQ, and SCARED are only reported for items with a convergent validity, $\rho>0.4$ (all other correlations are reported in Appendix II). For several condition-specific items the correlation were above the threshold (convergent validity, $\rho>0.4$ ) and below the threshold for most of the non-corresponding items (discriminant validity, $\rho<0.4$ ). More specifically; CPSS 13 (trouble sleeping) and MFQ 32 (less sleep than usual) correlated above the threshold with the sleep dimension; SDQ 3 (headaches, stomachaches, and sickness) correlated above the threshold with the discomfort and symptoms dimension of the 16D; SCARED 11 (get stomachaches at school) and SCARED 17 (worry about going to school) with the school and hobbies dimension of 16D, and; SCARED 7 (I am nervous), SCARED 23 (I am a worrier), SCARED 24 (I get really frightened for no reason), SCARED 30 (I am afraid of having anxiety attacks), SCARED 35 (I worry about how well I do things) and SDQ8 (I worry a lot) with the distress dimension of 16D. 
Table 3: Convergent validity by item-level correlations between condition-specific items and 16D dimensions. In bold are correlation with values $>0.4$.

\begin{tabular}{|c|c|c|c|c|c|c|c|}
\hline \multirow[b]{3}{*}{ CPSS } & \multirow[b]{3}{*}{ Sleeping } & \multirow[b]{3}{*}{ CPSS13 } & \multicolumn{5}{|c|}{$16 \mathrm{D}$} \\
\hline & & & \multirow{2}{*}{$\begin{array}{l}\text { Sleeping } \\
0.543^{* *}\end{array}$} & \multirow{2}{*}{$\begin{array}{l}\text { Distress } \\
0.110\end{array}$} & \multirow{2}{*}{ 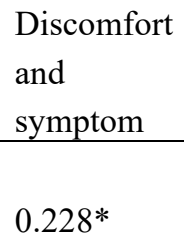 } & \multirow{2}{*}{$\begin{array}{l}\text { Mental } \\
0.150\end{array}$} & \multirow{2}{*}{ 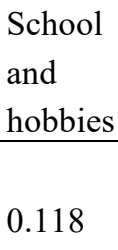 } \\
\hline & & & & & & & \\
\hline MFQ & Sleeping & MFQ32 & $0.507 * *$ & 0.128 & 0.145 & $0.207^{*}$ & 0.146 \\
\hline \multirow[t]{2}{*}{ SDQ } & Distress & SDQ8 & $0.239 * *$ & $0.542^{* *}$ & $0.252^{* *}$ & $0.240 * *$ & $0.217 * *$ \\
\hline & $\begin{array}{l}\text { Discomfort } \\
\text { and symptom }\end{array}$ & SDQ3 & $0.294 * *$ & $0.218^{* *}$ & $0.428^{* *}$ & $0.230 * *$ & $0.310^{* *}$ \\
\hline \multirow[t]{7}{*}{ SCARED } & Distress & SCARED7 & 0.143 & $0.525^{* *}$ & $0.210^{*}$ & $0.272 * *$ & 0.157 \\
\hline & & SCARED23 & $0.224 * *$ & $0.559 * *$ & $0.236^{* *}$ & $0.256^{* *}$ & $0.241 * *$ \\
\hline & & SCARED24 & $0.238 * *$ & $0.433 * *$ & $0.312^{* *}$ & $0.331 * *$ & $0.18^{*}$ \\
\hline & & SCARED30 & $0.185^{*}$ & $0.419^{* *}$ & $0.254^{* *}$ & $0.272 * *$ & 0.119 \\
\hline & & SCARED35 & 0.047 & $0.402 * *$ & $0.203^{*}$ & $0.282 * *$ & $0.260 * *$ \\
\hline & $\begin{array}{l}\text { School and } \\
\text { hobbies }\end{array}$ & SCARED11 & $0.276^{* *}$ & $0.278^{* *}$ & $0.412^{* *}$ & $0.207^{*}$ & $0.420 * *$ \\
\hline & & SCARED17 & $0.23 * *$ & $0.341 * *$ & $0.204 *$ & $0.223 * *$ & $0.405^{* *}$ \\
\hline
\end{tabular}

\subsection{Criterion Validity}

The 16D HRQoL score was significantly correlated with all the condition-specific instruments (CPSS, MFQ, SCARED, and SDQ). As shown in Table 4, the correlation coefficient was significant for all measures, with the strongest correlation to SCARED (-0.659). We also observe that SCARED is the condition-specific instrument that has the strongest correlation to all instruments.

Table 4: Correlation between the 16D and CPSS, MFQ, SDQ and SCARED at baseline.

\begin{tabular}{llllll}
\hline Instrument & $16 \mathrm{D}$ & CPSS & MFQ & SDQ & SCARED \\
\hline 16D & 1 & & & & \\
CPSS & $-0.497^{* *}$ & 1 & & & \\
MFQ & $-0.472^{* *}$ & $0.501^{* *}$ & 1 & & \\
SDQ & $-0.547^{* *}$ & $0.477^{* *}$ & $0.567^{* *}$ & 1 & \\
SCARED & $-0.659^{* *}$ & $0.585^{* *}$ & $0.631^{* *}$ & $0.696^{* *}$ & 1 \\
\hline $\mathrm{N}$ & 149 & 149 & 149 & 149 & 147 \\
\hline
\end{tabular}

**significant at $\mathrm{p}<0.01$

\subsection{Comparative analysis}

In Table 5, the differences in VAS-scores for each of the 16 dimensions were estimated by subtracting the 16D scores from the representative sample Finnish schoolchildren with the 16D scores in the PTSD group (Rios-Diaz et al., 2016). The health difference was highest for depression $(0.347)$ and lowest for mobility (0.012). The mean difference was statistically significant $(\mathrm{p}<.05)$ for all dimensions, indicating that, as expected, the children and adolescents with PTSD had lower 
baseline VAS-scores than the representative sample of Finnish schoolchildren. The effect size measured by the Cohen's d coefficient showed a large effect between most items, with the exception of dimensions friends and speech, with a medium effect, and vision, hearing, mobility, and excretion with a low effect.

The 16D overall HRQoL score was significantly lower (0.177) for the PTSD group than for the Finnish sample of schoolchildren. On average, the 16D score for the PTSD group was 0.766, while the mean score was 0.943 among the Finnish schoolchildren. (Table 5). The estimated Cohen's $\mathrm{d}$ coefficient for the total population was 1.07 , showing a large effect size and demonstrating that these two groups are different.

Table 5: Health differences $(\Delta)$ in PTSD children and adolescents compared to a general Finnish sample (12-15) years, for the PTSD sample.

\begin{tabular}{|c|c|c|c|c|}
\hline \multirow[b]{2}{*}{ 16D dimension } & \multicolumn{4}{|c|}{ Mean VAS score by dimension } \\
\hline & PTSD Sample & $\begin{array}{l}\text { Finnish } \\
\text { schoolchildren }\end{array}$ & $\Delta$ mean scores $*$ & Cohen's d \\
\hline Vitality & 0.549 & 0.831 & 0.282 & $0.764 *$ \\
\hline Seeing & 0.888 & 0.949 & 0.061 & 0.240 \\
\hline Breathing & 0.771 & 0.964 & 0.193 & 0.590 \\
\hline Distress & 0.574 & 0.878 & 0.304 & $0.890^{*}$ \\
\hline Hearing & 0.957 & 0.984 & 0.027 & 0.185 \\
\hline Sleeping & 0.566 & 0.901 & 0.334 & 0.947 \\
\hline Eating & 0.885 & 1.000 & 0.115 & 0.559 \\
\hline Discomfort and & & & & \\
\hline symptoms & 0.645 & 0.902 & 0.258 & 0.710 \\
\hline Physcial appearance & 0.648 & 0.896 & 0.249 & 0.620 \\
\hline School and hobbies & 0.672 & 0.974 & 0.302 & $0.985^{*}$ \\
\hline Moving & 0.988 & 1.000 & 0.012 & 0.169 \\
\hline Friends & 0.872 & 0.995 & 0.123 & 0.497 \\
\hline Mental functioning & 0.727 & 0.979 & 0.252 & 0.795 \\
\hline Elimination & 0.948 & 0.988 & 0.040 & 0.202 \\
\hline Depression & 0.550 & 0.897 & 0.347 & $0.979^{*}$ \\
\hline Speech & 0.837 & 0.956 & 0.118 & $0.431^{*}$ \\
\hline 16D score & 0.755 & 0.943 & 0.189 & \\
\hline
\end{tabular}

* all estimates significant at $\mathrm{p} \leq 0.05$

\section{Discussion}

The aim of this study was to compare the generic 16D instrument with several conditionspecific instruments (CPSS, SCARED, MFQ, and SDQ) to assess whether the 16D is a valid instrument for evaluating health outcomes in children and adolescents with PTSD.

We explored both content-, construct- and criterion validity. Our results revealed that overall HRQoL scores of the 16D correlate well with the condition-specific scores relevant to the population of children and adolescent with PTSD being studied. The results may not be generalizable to all other instruments measuring HRQoL and to all other areas of mental illness. For instance, in a study of adolescents with depression, EQ-5D did not correlate as strongly with the condition-specific instruments (Health of the Nation Outcome 
Scales Children and Adolescent Mental Health, MFQ, and the Children's Depression Rating Scale) as in our study (Byford, 2013). This could be explained that the EQ-5D only includes 5 dimensions of health rather than 16 in our study, which was confirmed in another study, where the 15D instrument was shown to be more appropriate than the EQ-5D when the two instruments were compared for 29 chronic conditions (Birmaher et al., 1999).

The construct validity were tested by inter-item correlation and satisfied the threshold for correlations between corresponding items $(\rho>0.4)$ within dimensions and below the threshold $(\rho<0.4)$ for most of the correlations between non-corresponding items. However, many corresponding items of condition-specific instrument were not correlated to the similar dimension in the 16D (full results are reported in Appendix II). This could be due to the fact that the items of condition-specific instruments address a more narrow range of health problems than what is captured by the broadly defined 16D dimension- For example, the SCARED 11 (get stomachaches at school) item could be classified under both the feeling discomfort and the worries about being at school dimensions of the 16D, whereas the SCARED17 (worries about going to school) would most likely relate only to the latter dimension.

The children and adolescents with PTSS had a health difference of 0.177 when they were compared to a representative sample of Finnish 12-15-year-old schoolchildren and reported significant health differences in all 16 dimensions. The health difference measured in this group is higher than the difference reported in a previous study of adolescents suffering from inflammatory bowel disease (Mihalopoulos et al., 2014) and among children with skeletal dysplasia and epilepsy (Apajasalo et al., 1998; Haapamaki et al., 2011), at 0.916 and 0.947, respectively. The children and adolescents with PTSD seemed to have the highest health difference in the depression dimension, followed by sleeping, distress, school and hobbies, vitality, and discomfort and symptoms. This appears to be consistent with the most common dimensions addressed by four condition-specific instruments (CPSS, SCARED, MFQ, and SDQ), which had been identified as sleeping, distress, school and hobbies, discomfort and symptoms, and mental dimensions. Further, we observed that children and adolescents with PTSD had a significant health differences in dimensions, not included in the condition-specific instruments (vitality, breathing, physical appearance, breathing, friends, and speech). Therefore, the 16D instrument capture additional dimensions of health for the PTSD population, no covered by the condition-specific instruments.

The mean baseline 16D HRQoL score for the PTSD group was 0.766 (vs. 0.943 for the representative sample of Finnish schoolchildren), which shows an average health difference of 0.177. In absence of treatment, this would accumulate to a substantial QALYs lost in future health compared to the general population. In Norway, severity is one of the pillars of priority settings (White paper, 2015), and should be measured by absolute shortfall, defined as the future loss in QALYs as a result of the condition compared to not having the condition. In reimbursement decision, the threshold value for an incremental QALY is increasing with severity. Therefore, as the PTSD groups is relatively young, it is likely that incremental QALY gains will be given a high threshold value.

While many studies have reported mixed opinions about the use of generic measures, especially for mental health problems in children and adolescents (Rios-Diaz et al., 2016; Crawford et al., 2011; Saarni et al., 2010; Brazier et al., 2014; Mulhern et al., 2014; Byford, 2013; Bastiaansen et al., 2004; Solans et al., 2008), the findings in our study show that the 16D could be an appropriate instrument for the assessment of HRQoL in patients presenting with PTSD. While it appears that the 16D captured more dimensions of health than the condition-specific instruments, it could lead to lower estimates of health in certain patients that are affected by other health problems unrelated to the one under evaluation. However, 
given that in CUA decisions are not concerned with absolute health effects but rather the relative effect between the old and new treatment, this problem would be minimized providing that the study participants were properly randomized between treatment arms in the RCT. However, this can be an important limitation to keep in mind.

The 16D instrument allows for comparison across diseases within mental and physical health that otherwise would not be easily comparable due to their different outcome units. Therefore, generic measures can be very useful when conducting cost-utility or costeffectiveness analyses that serve to assist decision-making in health care. The 16D has the added advantage of being easy to use and can be completed within 5-10 minutes (Apajasalo et al., 1996). Other generic instrument, such as the EQ-5D-Y, are available for this age group. The planning of the RCT started in 2008, and less instruments were tested and available, hence the choice of appropriate instrument were based on discussions within the research group based. The discussions where mainly related to the different dimensions of health, where the clinicians found the 16D to be the most relevant for the PTDS population. As several guidelines recommend the use of EQ-5D, future research should test the validity of other generic instruments for this patient group.

The study sample included children and adolescents from 10-18 years old. As the 16D was developed primarily for the age group 12-15 years, the questionnaire did not fit our study population perfectly. Ideally, the study should have included the 17D (8-11 years) and the 15D (16-18 years) to assess HRQoL more accurately. On the 15D website (15d.instrument.net), it is stated that the 16D questionnaire can also be used for the age group 16-18 years. When we explored age-group differences in our sample, we found that HRQoL scores among the youngest age group were generally higher. Whether the youngest age group is actually in better health or the higher HRQoL scores were a result of measurement error is difficult to determine determined. The latter would be a problem only when interpreting the findings. However, other plausible explanations for the higher scores can by formulated. For example, we could hypothesize that younger children had lived with their trauma for a much shorter period of time and may have experienced fewer traumas in general, leading to milder symptoms. It could also be related to their cognitive abilities to process their traumatic experiences. Therefore, we cannot state conclusively that the higher scores were due to measurement error and using the wrong instrument. When we organized the trial, balancing the total burden of questionnaires with the risk of low response rate and the likelihood of making mistakes in the allocation of questionnaires to the participants were among the factors discussed. We concluded that one questionnaire instead of three would probably ensure higher response rates and fewer errors. In addition, it was expected that most of the patients would be older than 12 years of age. Only $16 \%$ of the sample was younger than 12 years; therefore, the majority of the sample was within the acceptable age range for the $16 \mathrm{D}$.

Another potential area of concern is the fact that the preference weights were based on a representative sample of Finnish schoolchildren (12-15 years), which could be different from preferences in a similar Norwegian cohort. There is always a risk that values between countries are different due to cultural and other institutional settings (Norman et al., 2009).

In this study, we have included children and adolescents with different types of trauma, such as domestic and external violence, sexual abuse, and accidents. It could be argued that these traumas are too diverse to be analyzed as one group. If trauma caused by an accident influences HRQoL differently from sexual abuse, the correlation between the disease-specific measures might vary according to trauma. Due to few observations, we were not able to study the impact of various types of trauma on the correlation, but in future research projects, this heterogeneity could be explored. 
Lastly, this cross-sectional study did not have the data to assess responsiveness available at the time of these analyses. Further research is needed to conclusively determine whether the $16 \mathrm{D}$ is also sensitive to clinical changes in patients after they have received treatment. It should be noted that the results of this study pertain only to a subgroup of patients with clinically significant PTSS adolescents, namely patients who had CPSS scores of 15 and above and at least one symptom of each of three PTSD symptom criteria. The results of this study, however, may not be generalized to patients without clinically significant PTSS.

\section{Conclusion}

Our findings revealed that there were few non-responders, the $16 \mathrm{D}$ dimensions corresponding with items in the condition-specific instruments confirmed convergent validity for several of the items, and that the 16D HRQoL score was strongly correlated with all condition-specific instruments (CPSS, MFQ, SCARED, and SDQ) and most strongly with the SCARED score. Children and adolescent with PTSD have a significant lower health for all 16D dimensions. The latter indicates that the 16D assesses a wider range of health consequences than the condition-specific instruments in the context of PTSD. More studies need to be conducted to observe the responsiveness of the 16D in these groups and to verify whether condition-specific changes are correlated with the 16D.

\section{Acknowledgements}

We would like to thank the Research Council of Norway; Directorate for Health and Social Affairs; Norwegian Extra Foundation for Health and Rehabilitation; and the Norwegian Center for Violence and Traumatic Stress Studies for funding this study. In order to translate the questionnaire, we got valuable help from Gudrun MW Bjørnelv and Arna Desser, for which we are thankful. In addition, we would like to thank the two reviewers for valuable comments.

\section{Funding}

This project was funded by; the Research Council of Norway; Directorate for Health and Social Affairs; Norwegian Extra Foundation for Health and Rehabilitation; and the Norwegian Center for Violence and Traumatic Stress Studies.

\section{Conflicts of interest}

No conflicts of interest exist concerning the authors and the contents of this article.

\section{Ethical approval}

All procedures performed in studies involving human participants were in accordance with the ethical standards of the institutional and/or national research committee and with the 1964 Helsinki declaration and its later amendments or comparable ethical standards. Informed consent was obtained from all individual participants included in the study. 


\section{References}

Ackerman, P. T., Newton, J. E., McPherson, W. B., Jones, J. G., \& Dykman, R. A. (1998). Prevalence of post traumatic stress disorder and other psychiatric diagnoses in three groups of abused children (sexual, physical, and both). Child abuse \& neglect, 22(8), 759-774. https://doi.org/10.1016/s0145-2134(98)00062-3

Ajdukovic, M. (1998) Displaced adolescents in Croatia: sources of stress and posttraumatic stress reaction. Adolescence, 33(129): p. 209-17

American Educational Research Association, Psychological Association, \& National Council on Measurement in Education. (1999). Standards for Educational and Psychological Testing. Washington, DC: American Educational Research Association.

Apajasalo, M., Rautonen, J., Holmberg, C., Sinkkonen, J., Aalberg, V., Pihko, H., Siimes, M. A., Kaitila, I., Mäkelä, A., Erkkilä, K., \& Sintonen, H. (1996). Quality of life in pre-adolescence: a 17-dimensional health-related measure (17D). Quality of life research : an international journal of quality of life aspects of treatment, care and rehabilitation, 5(6), 532-538. https://doi.org/10.1007/BF00439227

Apajasalo, M., Sintonen, H., Rautonen, J., and Kaitila, I. (1998). Health-related quality of life of patients with genetic skeletal dysplasias. European Journal of Pediatrics, 157(2), 114-121

Bastiaansen, D., Koot, H. M., Bonger, I. L., Varni, J. W. and Verhulst, F. C. (2004). Measuring quality of life in children referred for psychiatric problems: Psychometric properties of the PedsQLTM 4.0 generic core scales. Quality of Life Research, 13(2): p. 489-495.

Birmaher, B., Khetarpal, S., Brent, D., Cully, M., Balach, L., Kaufman, J., \& Neer, S. M. (1997). The Screen for Child Anxiety Related Emotional Disorders (SCARED): scale construction and psychometric characteristics. Journal of the American Academy of Child and Adolescent Psychiatry, 36(4), 545-553. https://doi.org/10.1097/00004583-199704000-00018

Birmaher, B., Brent, D. A., Chiappetta, L., Bridge, J., Monga, S., \& Baugher, M. (1999). Psychometric properties of the Screen for Child Anxiety Related Emotional Disorders (SCARED): a replication study. Journal of the American Academy of Child and Adolescent Psychiatry, 38(10), 1230-1236. https://doi.org/10.1097/00004583-199910000-00011

Brazier, J., Connell, J., Pappaioannou, D., Mukuria, C., Mulhern, B., Peasgood, T., Jones, M. L., Paisley, S., O'Cathain, A., Barkham, M., Knapp, M., Byford, S., Gilbody, S. and Parry, G. (2014). A systematic review, psychometric analysis and qualitative assessment of generic preference-based measures of health in mental health populations and the estimation of mapping functions from widely used specific measures. Health Technology Assessment, 18(34): p. vii-viii, xiii-xxv, 1-188.

Byford, S. (2013) The validity and responsiveness of the EQ-5D measure of health-related quality of life in an adolescent population with persistent major depression. Journal of Mental Health, 22(2): p. $101-10$

Bøe, T., Hysing, M., Skogen, J. C., \& Breivik, K. (2016). The Strengths and Difficulties Questionnaire (SDQ): Factor Structure and Gender Equivalence in Norwegian Adolescents. PloS one, 11(5), e0152202. https://doi.org/10.1371/journal.pone.0152202 Costello, E.J. and Angold, A. (1988). Scales to Assess Child and Adolescent Depression: Checklists, Screens, and Nets. Journal of the American Academy of Child \& Adolescent Psychiatry, 27(6): p. 726-737

Copeland, W.E., Keeler, G. and Angold, A. (2007). Traumatic events and posttraumatic stress in childhood. Archive of General Psychiatry, 64(5): p. 577-84.

Crawford, M.J., Robotham, D., Thana, L., Patterson, S., Weaver, T., Barber, R., Wykes, T. and Rose, D. (2011). Selecting outcome measures in mental health: the views of service users. Joutnal of Mental Health, 20(4): p. 336-46

Drummond, M. F., Sculpher, M. J., Claxton, K., Stoddart, G. L., and Torrance, G. W. (2015). Methods for the economic evaluation of health care programmes: Oxford university press. 
Eiser, C., (1997), Children's quality of life measures. Archives of Disease in Childhood, 77(4): p. 350-354

Fairbank, J.A. and D.W. Fairbank. (2009) Epidemiology of child traumatic stress. Current Psychiatry Report, 11(4): p. 289-95.

Finkelhor, D. (1994). The international epidemiology of child sexual abuse. Children Abuse and Neglect, 18(5): p. 409-17

Foa, E. B., Johnson, K. M., Feeny, N. C., \& Treadwell, K. R. H. (2001). The Child PTSD Symptom Scale: A preliminary examination of its psychometric properties. Journal of Clinical Child Psychology, 30(3), 376-384.

Gilbert, R., Widom, C. S., Browne, K., Fergusson, D., Webb, E., \& Janson, S. (2009). Burden and consequences of child maltreatment in high-income countries. Lancet (London, England), 373(9657), 68-81. https://doi.org/10.1016/S0140-6736(08)61706-7

Goodman, R. (2001) Psychometric properties of the strengths and difficulties questionnaire. Journal of the American Academy of Child \& Adolescent Psychiatry, 40(11): p. 1337-45

Guideline for the Conduct of Economic Evaluations in Health Care, Dutch National Health Care Institute, Editor. 2016: Netherlands.

Guidelines for the economic evaluation of health technologies: Canada. 4th ed., CADTH, Editor. 2017: Ottawa.

Haapamaki, J., Roine, R. P., Sintonen, H. and Kohlo, K-L. (2011). Health-related quality of life in paediatric patients with inflammatory bowel disease related to disease activity. Journal of Paediatric Child Health, 47(11): p. 832-7

Harding, L. (2001) Children's quality of life assessments: A review of generic and health related quality of life measures completed by children and adolescents. Clinical Psychology and Psychotherapy, 8(2): p. 79-96

Hukkelberg, S.S. and Jensen, T. K. (2011) The dimensionality of posttraumatic stress symptoms and their relationship to depression in children and adolescents. Journal of Trauma and Stress, 24(3): p. 326-33.

Hukkelberg, S., Ormhaug, S. M., Holt, T., Wentzel-Larsen, T., \& Jensen, T. K. (2014). Diagnostic utility of CPSS vs. CAPS-CA for assessing posttraumatic stress symptoms in children and adolescents. Journal of anxiety disorders, 28(1), 51-56. https://doi.org/10.1016/j.janxdis.2013.11.0016.

Jensen, T.K., G. Dyb, and E. Nygaard. (2009). A longitudinal study of posttraumatic stress reactions in Norwegian children and adolescents exposed to the 2004 tsunami. Archives of Pediatrics and Adolescent Medicine, 163(9): p. 856-61

Jensen, T. K., Holt, T., Ormhaug, S. M., Egeland, K., Granly, L., Hoaas, L. C., Hukkelberg, S. S., Indregard, T., Stormyren, S. D., \& Wentzel-Larsen, T. (2014). A randomized effectiveness study comparing trauma-focused cognitive behavioral therapy with therapy as usual for youth. Journal of clinical child and adolescent psychology : the official journal for the Society of Clinical Child and Adolescent Psychology, American Psychological Association, Division 53, 43(3), 356-369. https://doi.org/10.1080/15374416.2013.822307

Kassam-Adams, N., Marsac, M. L. and Cirilli, C. (2010). Posttraumatic stress disorder symptom structure in injured children: functional impairment and depression symptoms in a confirmatory factor analysis. Journal of American Academy of Child Adolescent Psychiatry, 49(6): p. 616$25,625 . \mathrm{e} 1-4$

Kilpatrick, D. G., Ruggiero, K. J., Acierno, R., Saunders, B. E., Resnick, H. S., \& Best, C. L. (2003). Violence and risk of PTSD, major depression, substance abuse/dependence, and comorbidity: results from the National Survey of Adolescents. Journal of consulting and clinical psychology, 71(4), 692-700. https://doi.org/10.1037/0022-006x.71.4.69220.

McLaughlin, K. A., Koenen, K. C., Hill, E. D., Petukhova, M., Sampson, N. A., Zaslavsky, A. M., \& Kessler, R. C. (2013). Trauma exposure and posttraumatic stress disorder in a national sample 
of adolescents. Journal of the American Academy of Child and Adolescent Psychiatry, 52(8), 815-830.e14. https://doi.org/10.1016/j.jaac.2013.05.011

Meiser-Stedman, R., Smith, P., Glucksman, E., Yule, W., \& Dalgleish, T. (2008). The posttraumatic stress disorder diagnosis in preschool- and elementary school-age children exposed to motor vehicle accidents. The American journal of psychiatry, 165(10), 1326-1337. https://doi.org/10.1176/appi.ajp.2008.0708128

Mihalopoulos, C., Chen, G., Iezzi, A., Khan, M. A., \& Richardson, J. (2014). Assessing outcomes for cost-utility analysis in depression: comparison of five multi-attribute utility instruments with two depression-specific outcome measures. The British journal of psychiatry : the journal of mental science, 205(5), 390-397. https://doi.org/10.1192/bjp.bp.113.136036

Mulhern, B., Mukuria, C., Barkham, M., Knapp, M., Byford, S., Soeteman, D. and Brazier, J. (2014). Using generic preference-based measures in mental health: psychometric validity of the EQ5D and SF-6D. The British Journal of Psychiatry, 205(3): p. 236-243

Norman, R., Cronin, P., Viney, R., King, M., Street, D., \& Ratcliffe, J. (2009). International comparisons in valuing EQ-5D health states: a review and analysis. Value in health : the journal of the International Society for Pharmacoeconomics and Outcomes Research, 12(8), 11941200. https://doi.org/10.1111/j.1524-4733.2009.00581.x

Petrou, S. (2003). Methodological issues raised by preference-based approaches to measuring the health status of children. Health Economics, 12(8): p. 697-702.

Retningslinjer for dokumentasjonsgrunnlag for hurtig metodevurdering av legemidler, Norwegian Medicines Agency, Editor. 2018: Oslo.

Ribbe, D. (1996). Psychometric reveiew of Traumatic Event Screening Instrument for Children (TESI-C) in Measurement of stress, trauma, and adaptation. 1996, Sidran Press: Lutherville, New York. p. 386-387.

Rios-Diaz, A.J., Lam, J., Ramos, M. S., Moscoso, A. V., Vaughn, P., Zogg, C. K. and Caterson, E. J. (2016) Global Patterns of QALY and DALY Use in Surgical Cost-Utility Analyses: A Systematic Review. PLoS One, 11(2): p. e0148304

Ronning, J.A., Handegaard, B. H., Sourander, A. and Mørch, W-T. (2004). The Strengths and Difficulties Self-Report Questionnaire as a screening instrument in Norwegian community samples. European Child and Adolescent Psychiatry, 13(2): p. 73-82

Saarni, S.I., Viertiö, S., Perälä, J., Koskinen, S., Lönnqvist, J. and Suvisaari, J. (2010). Quality of life of people with schizophrenia, bipolar disorder and other psychotic disorders. British Journal of Psychiatry, 197(5): p. 386-94

Saxe, G. N., Stoddard, F., Hall, E., Chawla, N., Lopez, C., Sheridan, R., King, D., King, L., \& Yehuda, R. (2005). Pathways to PTSD, part I: Children with burns. The American journal of psychiatry, 162(7), 1299-1304. https://doi.org/10.1176/appi.ajp.162.7.1299

Solans, M., et al., Pane, S., Estrada, M. D., Serra-Sutton, V., Berra, S., Herdman, M., Alonso, J. and Rajmil, J. (2008) Health-Related Quality of Life Measurement in Children and Adolescents: A Systematic Review of Generic and Disease-Specific Instruments. Value in Health, 11(4): p. 742-764.

Sund, A.M., Larsson, B. and Wichstrøm, L. (2001). Depressive symptoms among young Norwegian adolescents as measured by The Mood and Feelings Questionnaire (MFQ). European Child \& Adolescent Psychiatry, 10(4): p. 222-229

White paper 34 (2015-2016). Verdier I pasientens helsetjeneste - Melding om prioritering. Ministry of Health and Social care. Norway 2015.

(C) 2020 by the author(s). This article is an open access article distributed under the terms and conditions of the Creative Commons Attribution license (http://creativecommons.org/licenses/by/4.0/). 


\section{Appendix I}

\section{Questionnaire 16D}

Question 1

- I feel healthy and energetic

○ I feel slightly weary, tired or weak

- I feel moderately weary, tired or weak

- I feel very weary, tired or weak

○ I feel extremely weary, tired or weak

Question 2

- I can easily see words in books and TV text without glasses

- I can easily see words in books and TV text with glasses

- I cannot easily see words in books and TV text, even with glasses

- I cannot read books and TV text, even with glasses, but I can see well enough to walk without a guide

- I cannot see well enough to walk without a guide, i.e. I am almost or totally blind

Question 3

- I do not have any breathing problems

- I get breathless during heavy work or sports, or when walking fast on flat ground or slightly uphill (not the same as being out of breath after running)

- I get breathless when walking on flat ground

- I get breathless even with the lightest activity, e.g. washing or dressing myself

- I am breathless almost all the time, even when resting

Question 4

- I do not feel at all anxious, stressed or nervous

- I feel slightly anxious, stressed or nervous

- I feel moderately anxious, stressed or nervous

- I feel very anxious, stressed or nervous

- I feel extremely anxious, stressed or nervous

Question 5

- I hear normal speech well without a hearing aid

- I hear normal speech with slight difficulty, but I don't need a hearing aid

- I need a hearing aid, but I can hear well with it

- I hear poorly even with a hearing aid

$\circ$ I am totally deaf

Question 6

- I have no problems with sleeping

- I have slight problems with sleeping, e.g. it is sometimes difficult to fall asleep, or I sometimes wake up at night

- I have moderate problems with sleeping, e.g. restless sleep, or feeling I have not slept enough

- I have great problems with sleeping, e.g. I have to take sleeping pills often or every night, or I usually wake at night or too early in the morning

- I find sleeping almost impossible, even with full use of sleeping pills, or I stay awake most of the night 
Question 7

- I am able to eat without any difficulty

- I am able to eat with slight difficulty (e.g. slowly, clumsily or with special appliances)

- I need some help from another person in eating

- I am not able to feed myself at all, so I must be fed by someone else

- I am unable to eat at all, so I must be fed by tube or directly into my blood

Question 8

- I have no physical troubles or symptoms, e.g. pain, ache, feeling sick or itchy

- I have slight physical troubles or symptoms, e.g. pain, ache, feeling sick or itchy

- I have moderate physical troubles or symptoms, e.g. pain, ache, feeling sick or itchy

- I have severe physical troubles or symptoms, e.g. pain, ache, feeling sick or itchy

- I have unbearable physical troubles or symptoms, e.g. pain, ache, feeling sick or itchy

Question 9

- I am able to speak clearly, audibly and fluently

- I have slight difficulties with speaking, e.g. I sometimes stumble over words, or mumble, or my voice breaks

- I can make myself understood, but my speech is e.g. disjointed, faltering, stuttering or stammering.

- Most people have great difficulty understanding my speech

- I can only make myself understood by gestures

Question 10

- My weight, height and what I look like do not bother me

- My weight, height or what I look like bother me slightly

- My weight, height or what I look like bother me moderately

- My weight, height or what I look like bother me seriously

- My weight, height or what I look like bother me extremely

Question 11

- My state of health does not interfere with going to school or having hobbies

- My state of health makes it slightly difficult to go to school or have hobbies

- My state of health makes it moderately difficult to go to school or have hobbies

- My state of health makes it almost impossible to go to school or have hobbies

- My state of health makes it impossible to go to school or have hobbies

Question 12

- I can walk easily without an appliance (e.g. crutches or wheelchair)

- I have difficulty in walking, but I am able to walk without an appliance, e.g. crutches or wheel chair

- I cannot walk without an appliance, e.g. crutches or wheelchair, but with it

- I can move around well, moving around is very difficult, even with an appliance

- I cannot move around at all and I am bedridden

Question 13

- My state of health does not interfere with making friends or being with them

- My state of health makes it slightly difficult to make friends or be with them

- My state of health makes it moderately difficult to make friends or be with them

- My state of health makes it almost impossible to make friends or be with them

- My state of health makes it impossible to make friends or be with them 
Question 14

- I am able to think clearly and logically

- I have slight problems in thinking clearly and logically

- I have moderate problems in thinking clearly and logically

- I have serious problems in thinking clearly and logically

- I am totally confused and unsure of the time and where I am

\section{Question 15}

○ My bladder and bowels work normally

- I have a slight problem with my bladder or bowels, e.g. difficulties with urination, or hard or loose stools

- I have moderate problems with my bladder or bowels, e.g. occasional 'accidents', or bad constipation or diarrhoea

- I have serious problems with my bladder or bowels, e.g. frequent 'accidents', or need for enemas or catheters

- I have no control at all over my bladder or bowel functions

\section{Question 16}

- I do not feel at all sad, melancholic or depressed

- I feel slightly sad, melancholic or depressed

- I feel moderately sad, melancholic or depressed

- I feel very sad, melancholic or depressed

- I feel extremely sad, melancholic or depressed' 
Table A1: 16D level frequencies (\%) according to health dimension, $n=156$

\begin{tabular}{lllllll}
\hline \multicolumn{2}{l}{ Response category } & & & & \\
Health Dimension & 1 & 2 & 3 & 4 & 5 & Missing \\
\hline Vitality & 12.2 & 30.8 & 22.4 & 18.6 & 11.5 & 4.5 \\
Vision & 64.1 & 19.9 & 10.3 & 0.6 & 0 & 5.1 \\
Breathing & 47.4 & 34.0 & 6.4 & 6.4 & 1.3 & 4.5 \\
Distress & 11.5 & 37.8 & 12.7 & 15.4 & 7.1 & 4.5 \\
Hearing & 81.4 & 14.1 & 0 & 0 & 0 & 4.5 \\
Sleeping & 16.0 & 23.1 & 37.8 & 12.8 & 5.8 & 4.5 \\
Eating & 68.6 & 12.1 & 3.8 & 0 & 0 & 4.5 \\
Discomfort and symptoms & 27.6 & 34.0 & 25.6 & 8.3 & 0 & 4.5 \\
Speech & 53.8 & 35.9 & 4.5 & 1.3 & 0 & 4.5 \\
Physical appearance & 33.3 & 21.2 & 15.4 & 13.5 & 12.2 & 4.5 \\
School and hobbies & 28.8 & 34.6 & 25.6 & 5.1 & 1.3 & 4.5 \\
Mobility & 92.3 & 3.2 & 0 & 0 & 0 & 4.5 \\
Friends & 69.2 & 17.9 & 7.1 & 0.6 & 0.6 & 4.5 \\
Mental function & 41.7 & 34.6 & 15.4 & 2.6 & 1.3 & 4.5 \\
Elimination & 85.3 & 8.3 & 1.3 & 0.6 & 0 & 4.5 \\
Depression & 13.5 & 35.9 & 21.2 & 17.9 & 7.1 & 4.5 \\
\hline
\end{tabular}




\section{Questionnaire 2: The Child PTSD Symptom Scale (CPSS) with frequencies for each item, $n=156$}

\begin{tabular}{|c|c|c|c|c|c|c|}
\hline & & $\begin{array}{l}\text { Not at all } \\
\text { or only at } \\
\text { one time }\end{array}$ & $\begin{array}{l}\text { Once a } \\
\text { week } \\
\text { or less/ } \\
\text { once in } \\
\text { a while }\end{array}$ & $\begin{array}{l}2 \text { to } 4 \\
\text { times a } \\
\text { week/ } \\
\text { half the } \\
\text { time }\end{array}$ & $\begin{array}{l}5 \text { or more } \\
\text { times a } \\
\text { week/almost } \\
\text { always }\end{array}$ & $\begin{array}{l}\text { Missi } \\
\text { ng }\end{array}$ \\
\hline 1. & $\begin{array}{l}\text { Having upsetting thoughts or images about } \\
\text { the event that came into your head when you } \\
\text { didn't want them to }\end{array}$ & 3.8 & 25.0 & 39.7 & 31.4 & \\
\hline 2. & Having bad dreams or nightmares & 26.3 & 34.6 & 26.9 & 12.2 & \\
\hline 3. & $\begin{array}{l}\text { Acting or feeling as if the event was } \\
\text { happening again (hearing something or } \\
\text { seeing a picture about it and feeling as if I } \\
\text { am there again) }\end{array}$ & 35.9 & 39.1 & 19.2 & 5.8 & \\
\hline 4. & $\begin{array}{l}\text { Feeling upset when you think about it or hear } \\
\text { about the event (for example, feeling scared, } \\
\text { angry, sad, guilty, etc) }\end{array}$ & 4.5 & 22.4 & 42.9 & 30.1 & \\
\hline 5. & $\begin{array}{l}\text { Having feelings in your body when you } \\
\text { think about or hear about the event (for } \\
\text { example, breaking out into a sweat, heart } \\
\text { beating fast) }\end{array}$ & 22.4 & 30.8 & 32.7 & 14.1 & \\
\hline 6. & $\begin{array}{l}\text { Trying not to think about, talk about, or have } \\
\text { feelings about the event }\end{array}$ & 8.3 & 23.1 & 29.1 & 39.1 & \\
\hline 7. & $\begin{array}{l}\text { Trying to avoid activities, people, or places } \\
\text { that remind you of the traumatic event }\end{array}$ & 28.2 & 30.1 & 15.4 & 26.3 & \\
\hline 8. & $\begin{array}{l}\text { Not being able to remember an important } \\
\text { part of the upsetting event }\end{array}$ & 42.3 & 29.5 & 17.9 & 10.3 & \\
\hline 9. & $\begin{array}{l}\text { Having much less interest or doing things } \\
\text { you used to do }\end{array}$ & 29.5 & 26.9 & 27.6 & 16.0 & \\
\hline 10. & Not feeling close to people around you & 22.4 & 26.3 & 30.8 & 20.5 & \\
\hline 11. & $\begin{array}{l}\text { Not being able to have strong feelings (for } \\
\text { example, being unable to cry or unable to } \\
\text { feel happy) }\end{array}$ & 25.0 & 25.0 & 32.1 & 17.9 & \\
\hline 12. & $\begin{array}{l}\text { Feeling as if your future plans or hopes will } \\
\text { not come true (for example, you will not } \\
\text { have a job or getting married or having kids) }\end{array}$ & 26.9 & 23.7 & 23.7 & 25.6 & \\
\hline 13. & Having trouble falling or staying asleep & 10.3 & 19.2 & 26.3 & 44.2 & \\
\hline 14. & Feeling irritable or having fits of anger & 5.1 & 26.3 & 39.1 & 29.5 & \\
\hline 15. & $\begin{array}{l}\text { Having trouble concentrating (for example, } \\
\text { losing track of a story on the television, } \\
\text { forgetting what you read, not paying } \\
\text { attention in class) }\end{array}$ & 6.4 & 15.4 & 37.2 & 41.0 & \\
\hline 16. & $\begin{array}{l}\text { Being overly careful (for example, checking } \\
\text { to see who is around you and what is around } \\
\text { you) }\end{array}$ & 17.3 & 26.3 & 26.9 & 29.5 & \\
\hline 17. & $\begin{array}{l}\text { Being jumpy or easily startled (for example, } \\
\text { when someone walks up behind you) }\end{array}$ & 23.7 & 21.1 & 26.3 & 28.8 & \\
\hline
\end{tabular}




\section{Questionnaire 3: MOOD AND FEELINGS QUESTIONNAIRE (MFQ) with frequencies for each item, $n=156$}

\begin{tabular}{|c|c|c|c|c|}
\hline & Not True & Some times & True & Missing \\
\hline $\begin{array}{l}\text { To code, please use a checkmark ( } \square \text { ) for each } \\
\text { statement. }\end{array}$ & 3.3 & 51.3 & 45.5 & \\
\hline 1. I felt miserable or unhappy. & 28.8 & 57.1 & 14.1 & \\
\hline 2. I didn't enjoy anything at all. & 28.8 & 31.4 & 39.7 & \\
\hline 3. I was less hungry than usual. & 66.7 & 19.2 & 14.1 & \\
\hline 4. I ate more than usual. & 7.7 & 44.9 & 47.4 & \\
\hline 5. I felt so tired I just sat around and did nothing. & 46.8 & 31.4 & 21.8 & \\
\hline $\begin{array}{l}\text { 6. I was moving and walking more slowly than } \\
\text { usual. }\end{array}$ & 13.5 & 48.1 & 38.5 & \\
\hline 7. I was very restless. & 19.2 & 35.9 & 44.9 & \\
\hline 8. I felt I was no good anymore. & 23.7 & 37.8 & 38.5 & \\
\hline 9. I blamed myself for things that weren't my fault. & 11.5 & 44.9 & 43.6 & \\
\hline 10. It was hard for me to make up my mind. & 15.4 & 42.3 & 42.3 & \\
\hline 11. I felt grumpy and cross with my parents. & 16.0 & 41.0 & 42.9 & \\
\hline 12. I felt like talking less than usual. & 61.5 & 28.2 & 10.3 & \\
\hline 13. I was talking more slowly than usual. & 29.5 & 34.6 & 35.9 & \\
\hline 14. I cried a lot. & 25.6 & 41.0 & 33.3 & \\
\hline $\begin{array}{l}\text { 15. I thought there was nothing good for me in the } \\
\text { future. }\end{array}$ & 32.7 & 36.5 & 30.8 & \\
\hline 16. I thought that life wasn't worth living. & 30.1 & 36.5 & 33.3 & \\
\hline 17. I thought about death or dying. & 42.3 & 31.4 & 26.3 & \\
\hline $\begin{array}{l}\text { 18. I thought my family would be better off without } \\
\text { me. }\end{array}$ & 59.6 & 23.7 & 16.7 & \\
\hline $\begin{array}{l}\text { 19. I thought there was nothing good for me in the } \\
\text { future }\end{array}$ & 34.6 & 48.7 & 16.7 & \\
\hline 20. I didn't want to see my friends. & 5.1 & 33.3 & 61.5 & \\
\hline 21. I found it hard to think properly or concentrate. & 19.2 & 48.7 & 32.1 & \\
\hline 22. I thought bad things would happen to me. & 34.6 & 33.3 & 32.1 & \\
\hline 23. I hated myself. & 26.9 & 39.1 & 34.0 & \\
\hline 24. I felt I was a bad person. & 30.1 & 30.8 & 39.1 & \\
\hline 25. I thought I looked ugly. & 39.7 & 40.4 & 19.9 & \\
\hline 26. I worried about aches and pains. & 22.4 & 37.8 & 39.7 & \\
\hline 27. I felt lonely. & 41.7 & 30.8 & 27.6 & \\
\hline 28. I thought nobody really loved me. & 21.8 & 44.9 & 33.3 & \\
\hline 29. I didn't have any fun in school. & 21.8 & 35.9 & 42.3 & \\
\hline 30. I thought I could never be as good as other kids. & 32.7 & 41.0 & 26.3 & \\
\hline 31. I did everything wrong. & 17.9 & 26.9 & 55.1 & \\
\hline 32. I didn't sleep as well as I usually sleep. & 62.8 & 16.0 & 21.2 & \\
\hline 33. I slept a lot more than usual. & 17.9 & 52.6 & 29.5 & \\
\hline $\begin{array}{l}\text { 34. S/he wasn't as happy as usual, even when s/he } \\
\text { was praised or rewarded. }\end{array}$ & 3.3 & 51.3 & 45.5 & \\
\hline
\end{tabular}




\section{Questionnaire 4: Strengths and Difficulties Questionnaire (SDQ) with frequencies for each item, $n=156$}

\begin{tabular}{|c|c|c|c|c|}
\hline & Not True & $\begin{array}{l}\text { Somewhat } \\
\text { True }\end{array}$ & $\begin{array}{l}\text { Certainly } \\
\text { True }\end{array}$ & Missing \\
\hline $\begin{array}{l}\text { 1. I try to be nice to other people. I care about their } \\
\text { feelings }\end{array}$ & 1.3 & 23.7 & 73.7 & 1.3 \\
\hline 2. I am restless, I cannot stay still for long & 14.1 & 46.8 & 37.8 & 1.3 \\
\hline 3. I get a lot of headaches, stomach-aches or sickness & 16.7 & 34.0 & 48.1 & 1.3 \\
\hline $\begin{array}{l}\text { 4. I usually share with others, for example CD's games, } \\
\text { food }\end{array}$ & 8.3 & 31.4 & 59.0 & 1.3 \\
\hline 5. I get very angry and often lose my temper & 7.1 & 40.4 & 51.3 & 1.3 \\
\hline 6.I would rather be alone than with people of my age & 31.4 & 48.1 & 19.2 & 1.3 \\
\hline 7.I usually do as I am told & 16.0 & 64.1 & 18.6 & 1.3 \\
\hline 8. I worry a lot & 8.3 & 34.0 & 56.4 & 1.3 \\
\hline 9. I am helpful if someone is hurt, upset, or feeling ill & 0.6 & 15.4 & 82.7 & 1.3 \\
\hline 10. I am constantly fidgeting or squirming & 17.9 & 46.2 & 34.6 & 1.3 \\
\hline 11. I have one good friend of more & 1.3 & 19.9 & 77.6 & 1.3 \\
\hline 12. I fight a lot. I can make other people do what I want & 75.6 & 17.9 & 5.1 & 1.3 \\
\hline 13. I am often hungry, depressed or tearful & 13.5 & 43.6 & 41.7 & 1.3 \\
\hline 14.Other people my age generally like me & 10.3 & 40.4 & 48.1 & 1.3 \\
\hline $\begin{array}{l}\text { 15. I am easily distracted. I find it difficult to } \\
\text { concentrate }\end{array}$ & 6.4 & 28.8 & 63.5 & 1.3 \\
\hline $\begin{array}{l}\text { 16. I am nervous in new situation. I easily lose } \\
\text { confidence }\end{array}$ & 14.1 & 38.5 & 46.2 & 1.3 \\
\hline 17. I am kind to younger children & 1.9 & 24.4 & 72.4 & 1.3 \\
\hline 18. I am often accused of lying or cheating & 61.5 & 26.9 & 10.3 & 1.3 \\
\hline $\begin{array}{l}\text { 19. Other children or young people pick on me or bully } \\
\text { me }\end{array}$ & 69.9 & 25.0 & 3.8 & 1.3 \\
\hline $\begin{array}{l}\text { 20. I often offer to help other (Parents, teachers or } \\
\text { children) }\end{array}$ & 5.1 & 56.4 & 37.2 & 1.3 \\
\hline 21. I think before I do things & 15.4 & 59.6 & 23.7 & 1.3 \\
\hline $\begin{array}{l}\text { 22. I take things that are not mine from home, school or } \\
\text { elsewhere }\end{array}$ & 89.7 & 6.4 & 2.6 & 1.3 \\
\hline $\begin{array}{l}\text { 23. I get along better with adults than with people my } \\
\text { own age }\end{array}$ & 43.6 & 43.6 & 11.5 & 1.3 \\
\hline 24. I have many fears, I am easily scared & 23.7 & 39.1. & 35.9 & 1.3 \\
\hline 25. I finish the work I'm doing. My attention is good. & 56.4 & 38.5 & 3.8 & 1.3 \\
\hline
\end{tabular}




\section{Questionnaire 5: Screen for Child Anxiety Related Emotional Disorders (SCARED) with frequencies for each item, $n=156$}

\begin{tabular}{|c|c|c|c|c|}
\hline & $\begin{array}{l}\text { Not True or } \\
\text { Hardly Ever } \\
\text { True }\end{array}$ & $\begin{array}{l}\text { Somewhat true } \\
\text { or sometimes } \\
\text { true }\end{array}$ & $\begin{array}{l}\text { Very True } \\
\text { or Often } \\
\text { True }\end{array}$ & Missing \\
\hline 1. When I feel frightened, it is hard to breathe & 41.0 & 37.2 & 19.9 & 1.9 \\
\hline 2. I get headaches when I am at school. & 21.2 & 44.2 & 32.7 & 1.9 \\
\hline $\begin{array}{l}\text { 3. I don't like to be with people I don't know } \\
\text { well. }\end{array}$ & 32.1 & 34.6 & 31.4 & 1.9 \\
\hline 4. I get scared if I sleep away from home. & 76.9 & 15.4 & 5.8 & 1.9 \\
\hline 5. I worry about other people liking me. & 32.7 & 28.8 & 35.9 & 2.6 \\
\hline 6. When I get frightened, I feel like passing out. & 57.7 & 28.8 & 11.5 & 1.9 \\
\hline 7. I am nervous. & 18.6 & 47.4 & 32.1 & 1.9 \\
\hline 8. I follow my mother or father wherever they go. & 74.4 & 16.7 & 7.1 & 1.9 \\
\hline 9. People tell me that I look nervous. & 62.2 & 26.3 & 9.6 & 1.9 \\
\hline 10. I feel nervous with people I don't know well. & 32.7 & 41.0 & 24.4 & 1.9 \\
\hline 11. I get stomachaches at school. & 40.4 & 30.1 & 27.6 & 1.9 \\
\hline $\begin{array}{l}\text { 12. When I get frightened, I feel like I am going } \\
\text { crazy. }\end{array}$ & 50.0 & 31.4 & 16.7 & 1.9 \\
\hline 13. I worry about sleeping alone. & 53.8 & 21.2 & 23.1 & 1.9 \\
\hline 14. I worry about being as good as other kids. & 30.1 & 37.2 & 30.8 & 1.9 \\
\hline $\begin{array}{l}\text { 15. When I get frightened, I feel like things are } \\
\text { not real. }\end{array}$ & 40.4 & 37.8 & 19.9 & 1.9 \\
\hline $\begin{array}{l}\text { 16. I have nightmares about something bad } \\
\text { happening to my parents. }\end{array}$ & 58.3 & 21.8 & 17.3 & 2.6 \\
\hline 17. I worry about going to school. & 48.7 & 30.1 & 18.6 & 2.6 \\
\hline 18. When I get frightened, my heart beats fast. & 12.2 & 36.5 & 48.7 & 2.6 \\
\hline 19. I get shaky. & 19.2 & 41.7 & 36.5 & 2.6 \\
\hline $\begin{array}{l}\text { 20. I have nightmares about something bad } \\
\text { happening to me. }\end{array}$ & 41.0 & 26.9 & 29.5 & 2.6 \\
\hline 21. I worry about things working out for me. & 18.6 & 48.1 & 30.8 & 2.6 \\
\hline 22. When I get frightened, I sweat a lot. & 57.7 & 25.0 & 14.7 & 2.6 \\
\hline 23. I am a worrier. & 21.2 & 42.9 & 33.3 & 2.6 \\
\hline 24. I get really frightened for no reason at all. & 46.8 & 32.7 & 17.9 & 2.6 \\
\hline 25. I am afraid to be alone in the house. & 52.6 & 25.0 & 19.9 & 2.6 \\
\hline $\begin{array}{l}\text { 26. It is hard for me to talk with people I don't } \\
\text { know well. }\end{array}$ & 35.3 & 35.9 & 26.3 & 2.6 \\
\hline $\begin{array}{l}\text { 27. When I get frightened, I feel like I am } \\
\text { choking. }\end{array}$ & 63.5 & 18.6 & 15.4 & 2.6 \\
\hline 28. People tell me that I worry too much. & 39.7 & 36.5 & 21.2 & 2.6 \\
\hline 29. I don't like to be away from my family. & 51.3 & 32.1 & 14.1 & 2.6 \\
\hline
\end{tabular}




\begin{tabular}{|c|c|c|c|c|}
\hline $\begin{array}{l}\text { 30. I am afraid of having anxiety (or panic) } \\
\text { attacks. }\end{array}$ & 45.5 & 26.9 & 25.0 & 2.6 \\
\hline $\begin{array}{l}\text { 31. I worry that something bad might happen to } \\
\text { my parents. }\end{array}$ & 33.3 & 35.3 & 28.8 & 2.6 \\
\hline 32. I feel shy with people I don't know well. & 38.5 & 28.2 & 30.8 & 2.6 \\
\hline $\begin{array}{l}\text { 33. I worry about what is going to happen in the } \\
\text { future. }\end{array}$ & 17.9 & 42.9 & 36.5 & 2.6 \\
\hline 34. When I get frightened, I feel like throwing up & 62.8 & 15.4 & 19.2 & 2.6 \\
\hline 35. I worry about how well I do things. & 19.2 & 41.0 & 37.2 & 2.6 \\
\hline 36. I am scared to go to school. & 63.5 & 20.5 & 13.5 & 2.6 \\
\hline $\begin{array}{l}\text { 37. I worry about things that have already } \\
\text { happened. }\end{array}$ & 19.2 & 50.6 & 28.2 & 1.9 \\
\hline 38. When I get frightened, I feel dizzy. & 48.1 & 28.8 & 21.2 & 1.9 \\
\hline $\begin{array}{l}\text { 39. I feel nervous when I am with other children } \\
\text { or adults and I have to do something while they } \\
\text { watch me (for example: read aloud, speak, play a } \\
\text { game, play a sport). }\end{array}$ & 30.1 & 36.5 & 31.4 & 1.9 \\
\hline $\begin{array}{l}\text { 40. I feel nervous when I am going to parties, } \\
\text { dances, or any place where there will be people } \\
\text { that I don't know well. }\end{array}$ & 49.4 & 28.2 & 20.5 & 1.9 \\
\hline 41. I am shy. & 41.0 & 32.7 & 24.4 & 1.9 \\
\hline
\end{tabular}




\section{Appendix II}

Table 2A: Convergent validity according to similar items in the condition-specific instruments and 16D dimensions.

\begin{tabular}{|c|c|c|c|c|c|c|c|}
\hline & & & Sleeping & Distress & $\begin{array}{l}\text { Discomfort } \\
\text { and } \\
\text { symptoms }\end{array}$ & Mental & $\begin{array}{l}\text { School } \\
\text { and } \\
\text { hobbies }\end{array}$ \\
\hline \multirow{7}{*}{ CPSS } & \multirow{2}{*}{ Sleeping } & CPSS 2 & 0.153 & 0.108 & $0.180^{*}$ & $0.234 * *$ & 0.065 \\
\hline & & CPSS13 & $0.543 * *$ & 0.110 & $0.228^{*}$ & 0.150 & 0.118 \\
\hline & Distress & CPSS17 & 0.047 & $0.304 * *$ & $0.249 * *$ & $0.248^{*}$ & 0.132 \\
\hline & $\begin{array}{c}\text { Discomfort } \\
\text { and symptoms }\end{array}$ & CPSS5 & $0.180^{*}$ & $0.216 * *$ & $0.228 * *$ & $0.176^{*}$ & 0.99 \\
\hline & Mental & CPSS15 & 0.07 & 0.097 & 0.121 & $0.249 * *$ & $0.230 * *$ \\
\hline & School and & CPSS7 & 0.056 & $0.295 * *$ & $0.276 * *$ & $0.2^{*}$ & $0.171^{*}$ \\
\hline & hobbies & CPSS9 & 0.097 & $0.248 * *$ & $0.198^{*}$ & $0.217 * *$ & 0.135 \\
\hline \multirow{5}{*}{ MFQ } & Sleeping & MFQ32 & $0.507 * *$ & 0.128 & 0.145 & $0.207^{*}$ & 0.146 \\
\hline & Distress & MFQ7 & 0.048 & -0.096 & 0.029 & 0.062 & 0.003 \\
\hline & $\begin{array}{c}\text { Discomfort } \\
\text { and symptoms }\end{array}$ & MFQ26 & $0.19 *$ & $0.202 *$ & $0.233 * *$ & $0.161 *$ & 0.135 \\
\hline & Mental & MFQ21 & -0.011 & $0.166^{*}$ & 0.133 & $0.288 * *$ & $0.238 * *$ \\
\hline & $\begin{array}{c}\text { School and } \\
\text { hobbies }\end{array}$ & MFQ29 & 0.128 & $0.302 * *$ & 0.099 & $0.212 * *$ & $0.174 *$ \\
\hline \multirow{8}{*}{ SDQ } & \multirow[t]{5}{*}{ Distress } & SDQ2 & $0.190^{*}$ & 0.092 & $0.172 *$ & 0.124 & 0.052 \\
\hline & & SDQ8 & $0.239 * *$ & $0.542 * *$ & $0.252 * *$ & $0.240 * *$ & $0.217 * *$ \\
\hline & & SDQ10 & $0.251 * *$ & 0.145 & 0.003 & 0.143 & -0.028 \\
\hline & & SDQ16 & 0.094 & $0.257 * *$ & $0.246 * *$ & $0.307 * *$ & 0.094 \\
\hline & & SDQ24 & 0.22 & $0.370 * *$ & $0.216 * *$ & $0.307 * *$ & 0.157 \\
\hline & $\begin{array}{c}\text { Discomfort } \\
\text { and symptoms }\end{array}$ & SDQ3 & $0.294 * *$ & $0.218 * *$ & $0.428 * *$ & $0.230 * *$ & $0.310 * *$ \\
\hline & \multirow[t]{2}{*}{ Mental } & SDQ15 & $0.177 *$ & $0.219 * *$ & $0.206 * *$ & $0.265 * *$ & $0.279 * *$ \\
\hline & & SDQ25 & -0.115 & -0.151 & -0.061 & $-\overline{0.286 * *}$ & $-0.303 * *$ \\
\hline \multirow{25}{*}{ SCARED } & \multirow[t]{2}{*}{ Sleeping } & SCARED16 & $0.162 *$ & 0.021 & $0.221 * *$ & -0.001 & -0.007 \\
\hline & & SCARED20 & $0.302 * *$ & $0.252 * *$ & $0.185^{*}$ & $0.196^{*}$ & 0.043 \\
\hline & \multirow[t]{15}{*}{ Distress } & SCARED7 & 0.143 & $0.525 * *$ & $0.210^{*}$ & $0.272 * *$ & 0.157 \\
\hline & & SCARED9 & $0.202 *$ & $0.248 * *$ & $0.18^{*}$ & $0.299 * *$ & $0.165^{*}$ \\
\hline & & SCARED10 & -0.018 & $0.253 * *$ & 0.104 & $0.225 * *$ & 0.107 \\
\hline & & SCARED14 & $0.22 * *$ & $0.385 * *$ & 0.127 & $0.249 * *$ & $0.208^{*}$ \\
\hline & & SCARED19 & $0.324 * *$ & $0.377 * *$ & $0.338 * *$ & $0.384 * *$ & $0.25 * *$ \\
\hline & & SCARED23 & $0.224 * *$ & $0.559 * *$ & $0.236 * *$ & $0.256 * *$ & $0.241 * *$ \\
\hline & & SCARED24 & $0.238 * *$ & $0.433^{* *}$ & $0.312 * *$ & $0.331 * *$ & $0.18^{*}$ \\
\hline & & SCARED25 & $0.306 * *$ & $0.259 * *$ & $0.31 * *$ & $0.191^{*}$ & $0.181 *$ \\
\hline & & SCARED28 & $0.209^{*}$ & $0.379 * *$ & $0.228 * *$ & 0.149 & $0.216^{* *}$ \\
\hline & & SCARED30 & $0.185^{*}$ & $0.419 * *$ & $0.254 * *$ & $0.272 * *$ & 0.119 \\
\hline & & SCARED33 & 0.097 & $0.394 * *$ & 0.106 & 0.157 & 0.107 \\
\hline & & SCARED35 & 0.047 & $0.402 * *$ & $0.203^{*}$ & $0.282 * *$ & $0.260 * *$ \\
\hline & & SCARED37 & 0.115 & $0.394 * *$ & $0.343 * *$ & $0.275 * *$ & $0.202 *$ \\
\hline & & SCARED39 & 0.037 & $0.243 * *$ & $0.200 *$ & $0.218 * *$ & $0.271 * *$ \\
\hline & & SCARED40 & -0.048 & $0.334 * *$ & $0.188^{*}$ & $0.267 *$ & $0.180^{*}$ \\
\hline & \multirow{4}{*}{$\begin{array}{c}\text { Discomfort } \\
\text { and symptoms }\end{array}$} & SCARED6 & $0.341 * *$ & $0.409 * *$ & $0.323 * *$ & $0.318 * *$ & $0.222 * *$ \\
\hline & & SCARED27 & $0.320 * *$ & $0.269 * *$ & $0.302 * *$ & $0.314 * *$ & $0.176^{*}$ \\
\hline & & SCARED34 & $0.281 * *$ & $0.333^{* *}$ & $0.294 * *$ & $0.269 * *$ & $0.216^{* *}$ \\
\hline & & SCARED38 & $0.275 * *$ & $0.375 * *$ & $0.355 * *$ & $0.326 * *$ & $0.177^{*}$ \\
\hline & \multirow{4}{*}{$\begin{array}{c}\text { School and } \\
\text { hobbies }\end{array}$} & SCARED2 & $0.259 * *$ & $0.339 * *$ & $0.344 * *$ & $0.219 * *$ & $0.397 * *$ \\
\hline & & SCARED11 & $0.276 * *$ & $0.278 * *$ & $0.412 * *$ & $0.207^{*}$ & $0.420 * *$ \\
\hline & & SCARED17 & $0.23 * *$ & $0.341 * *$ & $0.204 *$ & $0.223 * *$ & $0.405 * *$ \\
\hline & & SCARED36 & $0.231 * *$ & $0.323 * *$ & $0.252 * *$ & $0.247 * *$ & $0.386 * *$ \\
\hline
\end{tabular}

